\title{
How to Ruin Sex Research
}

\author{
J. Michael Bailey ${ }^{1}[$
}

Received: 31 January 2019 / Accepted: 6 February 2019 / Published online: 21 February 2019

(c) Springer Science+Business Media, LLC, part of Springer Nature 2019

On November 10, 2018, my graduate student, Kevin Hsu, gave an invited presentation at the annual meeting of the Society for the Scientific Study of Sexuality (SSSS) in Montreal. The occasion was his receipt of the society's annual "Ira and Harriet Reiss Theory Award" for "the best social science article, chapter, or book published in the previous year in which theoretical explanations of human sexual attitudes and behaviors are developed." His paper was on gynandromorphophilic men, or men attracted to transwomen who have not had vaginoplasty but have penises (Hsu, Rosenthal, Miller, \& Bailey, 2016).

According to numerous sources, the talk was interesting and the audience was interested. However, an attendee repeatedly and aggressively interrupted the presentation. This person, the psychologist Christine Milrod, is closely associated with the World Professional Association for Transgender Health (WPATH) and with the position that more and younger persons should more easily obtain medical treatment to change their sexes (Milrod, 2014; Milrod \& Karasic, 2017; 4thWaveNow, 2017). Milrod also strongly objects to the scientifically wellstudied idea that gender dysphoria that begins after puberty in natal males is caused by autogynephilia, or a male's sexual arousal by the fantasy of being a woman. Milrod was asked repeatedly by the audience and the moderator to let the presenter continue. Milrod failed to ask any questions during the period reserved for them.

SSSS officials and membership discussed the incident. On November 15, 2018 the SSSS Executive Committee sent a mass e-mail entitled "Important Message to SSSS Members \& Annual Meeting Attendees." The message expressed concern, not about Milrod's behavior, but about Hsu's presentation:

The SSSS Executive Committee is aware of past and more recent incidents of language and behavior that has [sic] made transgender persons and other attendees feel unwelcome, unsupported, marginalized, or attacked at

\section{J. Michael Bailey \\ jm-bailey@northwestern.edu}

1 Department of Psychology, Northwestern University, 2029 Sheridan Rd, Evanston, IL 60208, USA our Annual Meetings. We apologize. We want to assure all Members and attendees that we fully support you and stand with you. We are trans-allies.

Although I was shocked by the SSSS statement, I should not have been. It is emblematic of recent trends (Akresh \& Villasenor, 2018). I believe it is also a terrible statement: poorly reasoned, cowardly, and exactly opposite of what it should have been. To the extent that the SSSS statement reflects the direction of that organization, SSSS is headed toward ruin, or at least ruin as an organization ostensibly supportive of scientific sex research.

In this Guest Editorial, I adopt the (hopefully) rhetorical assumption that the SSSS wants to ruin sex research, and offer advice-most of which the statement appears well on its way to enacting - about how to do so. Do not assume, however, that SSSS is uniquely swayed by the forces I identify and decry. They are also present, for example, in the International Academy of Sex Research, the organization associated with the Archives of Sexual Behavior. Indeed, they are ascendant in academia generally. I focus here on sex research, because that is what I know, and also because sex research is uniquely vulnerable right now.

\section{Advocate for Marginalized Groups}

Sex researchers often feel sympathy for marginalized groups, especially when the groups have been marginalized due to irrational intolerance of sexuality. I have sympathized with various marginalized groups throughout my career, starting with homosexual people (back when they were marginalized), then transsexuals, and recently pedophiles, among others. ${ }^{1}$

Members of sexually marginalized groups are human. This means that they will sometimes be tempted to make

\footnotetext{
1 Although my sympathy for pedophiles who have resisted acting on their sexual desire for children has been straightforward and unwavering, it also extends to many offending pedophiles who are usually punished far more harshly than research suggests is warranted by the harm they cause (Rind, Tromovitch, \& Bauserman, 1998; Stupple, 2014).
} 
unreasonable demands on scientists and accusations against scientists who resist those demands. I have occasionally angered members of sexually marginalized groups. For example, during the 1990s some gay men disliked the idea that there is an association between homosexuality and gender nonconformity. I have devoted considerable effort to studying this association, which I now consider beyond reasonable doubt. I have written about autogynephilia-also beyond reasonable doubt and a common reason why Western natal males become transsexual (Lawrence, 2012) - despite the livid reactions of some transsexuals. I have angered bisexual men by publishing research suggesting that some do not have bisexual arousal patterns (Rieger, Chivers, \& Bailey, 2005), while conceding bisexual identity and behavior clearly exist.

I have offended sexually marginalized group by prioritizing the goals of sex research - putting forward plausible hypotheses, collecting and publishing data, drawing conclusions from data rather than my preferences, and making clear and correct arguments to the best of my abilities - over advocating for anyone, including marginalized groups. I have done so even when some groups insisted that my sex research harmed them. If I had prioritized advocacy, I likely would have refrained from conducting, or at least publishing, the offending research. That would have harmed sex research and would not have benefited the offended groups in any defensible way.

Thinking about groups can mislead one into ignoring important variation within groups. Many gay men embrace gender nonconformity - witness the success (twice) of the U.S. television show "Queer Eye for the Straight Guy." And some-we do not know what proportion-of males who fantasize about being female not only admit their autogynephilia, they embrace it and express relief that they are not alone (Lawrence, 2012; Saotome-Westlake, 2016). Supporting transgender persons who oppose autogynephilia theory is failing to support (or more accurately silencing) those who support the theory. What to do? An advocate would go with the majority, I suppose, although it would be difficult to get an accurate survey count. A scientific sex researcher would open discussion, weigh in with knowledge and data, and feel no compunction. To the extent that some members of a marginalized group require that plausible or even factual ideas not be discussed, they need therapy more than advocacy.

\section{Don't Question People's Identities and Narratives}

Most people have various identities and life narratives, and few of us enjoy it when these are challenged. Questioning identities and narratives of marginalized groups may seem especially unkind.

If people's identities and narratives were always accurate, think how much simpler science would be. But most insightful persons can remember times when they misunderstood themselves. It is not possible for a scientist to provide good evidence regarding the accuracy of an identity or narrative without questioning it. Consider the following example: After my laboratory published a paper suggesting that bisexual men did not, in general, have bisexual arousal patterns (Rieger et al., 2005), we were approached by the President of the American Institute of Bisexuality (AIB), John Sylla. He did not agree that our findings applied to all, or even to most, bisexual-identified men. But instead of condemning us, Sylla persuaded the AIB to fund a research study in which the AIB had non-binding input into our design (Denizet-Lewis, 2014). This resulted in the first clear demonstration of bisexual arousal patterns among a subset of bisexual-identified men (Rosenthal, Sylva, Safron, \& Bailey, 2012). I did not expect those results. (I was, however, perfectly contented to obtain them.) Sylla did not know in advance that we would obtain them. We were united by our desire to know the truth.

Declining to question identities and narratives may soothe feelings in the short term. In the long term, it ruins sex research by closing off important questions from empirical investigation.

\section{Focus on Linguistic Sensitivity Rather than Efficient Communication}

The politically acceptable way to refer to phenomena recently called "transgender" seems to change weekly (e.g., Steinmetz, 2014a, b; Transgender terms and labels, n.d.). Changes occur not because of scientific discovery or scientific consensus. Rather, they usually occur because activists say terminology must change, in order to reduce offense. Rapidly changing and poorly justified acceptable terminology impedes scientific communication in several ways. First, the acceptable terminology is vetted not by sex researchers who understand the underlying scientific issues, but by activists who do not seem to care much about scientific precision. Second, it makes connecting past, present, and future scientific researches much more difficult. Third, it wastes scientists' time. Furthermore, activists appear rarely to be satisfied, virtually guaranteeing that capitulation now will lead to future changes as well.

\section{Follow the Example of Gender Studies}

Gender Studies evolved from "Women's Studies" and is transitioning in many universities to "Gender and Sexuality Studies." If one agrees with the classification of some disciplines as "Grievance Studies" (Lindsay, Boghossian, \& Pluckrose, 2018) — as I do - then Gender Studies was the first and remains the most influential of those. Gender Studies has been successful to the extent that it is represented in most universities. 
Its faculty and students have also been successful in having disproportionate influence in current social justice movements (Devlin, 2017).

Wikipedia lists three broad influences on gender studies: psychoanalytic theory, literary theory, and postmodernism ("Gender Studies," n.d.). None of these influences has strong scientific values, and indeed, psychoanalytic theory was the only one of the three that even pretended at science. Thus, it is not surprising that few gender studies programs evince scientific approaches.

Science is not the only thing worth studying. Literature and history are important disciplines that arguably should be included in all higher educational curricula, although neither is a branch of science. However, any discipline that intends to draw accurate conclusions about human nature, including the determinants of gender-related traits, has no hope of doing so without a scientific, non-ideological approach. Gender Studies has that ambition, but it has failed and is doomed to fail without reform. If Gender Studies has contributed a single surprising true insight, I do not know it.

\section{Focus on Moral and Political Implications and "Sensitivity" of Scientific Presentations and Publications Rather Than on the Accuracy of Their Scientific Content}

Sex researchers are trained to do empirical (usually but not always scientific) sex research. They are not trained in moral philosophy, and I have not noticed the quality of their moral arguments to be especially high, even when the arguments pertain to sex-related issues. The few exceptions-notably including the founder of IASR and Archives of Sexual Behavior, Richard Green-have engaged in extensive study before writing outside empirical sex research. Green, for example, graduated from Yale Law School (Green, 2018). But Green is better known as a sex researcher than a legal scholar, and for good reason: legal/political/policy opinions are common and cheap, but scientific data of the kind Green collected are rare and expensive. Furthermore, despite Green's unusually intensive legal education, he has devoted more of his life and career to sex research than to law. He is primarily a sex researcher.

Getting the scientific part of sex research right is hard enough. Recently, we have become aware that many scientists have been getting it wrong. Many scientific publications have reported effects that are false, in the most important sense that they do not replicate in large studies. It is possible, in fact, that most published scientific findings have been false, at least until recently (IIoannidis, 2005). Science is hard.

Focusing on nonscientific aspects of sex research at the expense of the scientific aspects ruins sex research by diverting sex researchers from a difficult task that they have been trained to do and focusing them instead on tasks that they are not good at, in ways that are as likely to make the world worse as better. Good research practices tend to lead to discovery and verification of true ideas. In contrast, there is no telling which direction good intentions will lead.

\section{Discourage Discussion of Controversial Ideas}

Some ideas are bound to lead to heated arguments, claims of hurt feelings and other injury, and accusations of ill will. It is human to want to avoid these outcomes and to think badly of those who do not avoid them. But this reaction is misplaced.

Copernicus, Galileo, Darwin, Hirschfeld, and Kinsey all put forward ideas that were more accurate than competing ideas of their days. All caused claims of hurt feelings and other injury, and all had their motivations questioned. In none of these cases would either scientific or social progress have been furthered by silencing or "no-platforming" the scholars, or otherwise discouraging discussion of their ideas. This is not to say that ideas that offend are always correct; they usually are not. (Nor are scientific ideas that people prefer for unscientific reasons usually correct.) But these examples should remind us how imperfect we are at knowing what is true in early stages of systematic scientific inquiry. They should also remind us how ideological prejudice can mislead us.

The best way to discourage people from believing something is to show that it is false. There are still a few people in the U.S. who believe the earth is flat. Too many believe that vaccinations cause autism, not to mention the idea that global warming has nothing to do with human activity. Can anyone doubt that if we forcibly prevented people from voicing their opinions that the earth is flat, vaccinations cause autism, or that man-made global warming is illusory, believers would grow in number?

If people knew which ideas had merit and which did not even before the ideas had been thoroughly discussed and tested, then we would not need science. If we allowed a committee to decide on an unscientific basis which ideas should and should not be discussed, then the committee would be unscientifically promoting favored ideas by repressing others. Repression has often been justified on the basis that it was necessary for social justice or other world improvements. A thorough historical study of the successes and failures of these attempts should be part of every person's education. Vigorous and successful repression would unquestionably ruin sex research.

\section{Why Sex Research, and Why 2019?}

Although the world has become increasingly politically polarized (Edsall, 2012) and the university especially so (e.g., Lukianoff \& Haidt, 2018), there can be no doubt that sex research is 
among the most ideologically suspect of disciplines. For decades, sex research has been assailed by social conservatives, who accused sex researchers of political bias (Carey, 2004), sometimes accurately (Udry, 1993). Sex researchers have undoubtedly been sympathetic to certain goals, on average, including maintaining access to abortion, increasing gay rights, such as the right to gay marriage, and opposing abstinence sex education, among others. During the past decade, some of the goals favored by progressive sex researchers have been met, especially gay rights, including gay marriage.

Rather than basking in triumph, activists and activist-sympathetic sex researchers have sought "progress" (in the progressive sense) on other issues. Surely the most prominent issues in the past few years have concerned the transgender, including their conceptualization, treatment, and rights (Allen, 2015; Steinmetz, 2014a, b). But this "progress" has had nothing to do with scientific advances and everything to do with ideology. Considering any of the following is ideologically off limits for the progressive: Whether a male who says he is a woman may differ importantly from natal women; whether an adolescent girl who decides she is transgender might be wrong; whether gender-dysphoric children should be required to wait before "gender affirmation;" or whether transgender males who dislike autogynephilia theory may be in denial. No wonder that Christine Milrod attacked Kevin Hsu's SSSS presentation-it included a discussion of autogynephilia. And no wonder that the activist-sympathetic organization SSSS took her attack seriously.

I have been a sex researcher for more than 30 years. I have previously observed trends that I disliked, such as the postmodern intrusion of the 1980s and 1990s (for examples of this intrusion in sex research, see anything by Michel Foucault or Judith Butler; for others' criticisms of this intrusion, see e.g., Gross, Levitt, \& Lewis, 1996). However, I have never been as worried about the future of sex research specifically, and social science generally, as I have been in recent years. Now is a crucial time, and sex research is a crucial venue.

\section{How to Save Sex Research from Ruination}

If we want not the ruination of sex research but its opposite, what should we do? The first advice I have is easy to say but harder to do: Resist the trends and inclinations I have outlined above. Resistance is costly with respect to time and aggravation. Resistance may also be reputationally costly if one is falsely accused of any of a number of terrible-sounding things such as homophobia, transphobia, misogyny, or rape apology, among many other potential (and awful) accusations. But do not imagine that demands for ideological conformity will ever be satiated. If one fails to resist at any point, one is likely to confront a more extreme choice later (Akresh \& Villasenor, 2018; "First They Came," n.d.; Orwell, 1969).
My second piece of advice is less difficult: Do sex research, and do it well. The goal of sex research should be to discover things about sex, broadly construed, that are true and important. Anyone engaged in this kind of sex research cannot be making the world worse.

\section{References}

Akresh, I. R., \& Villasenor, J. (2018). How ritualized apologies are undermining freedom of expression. Quillette. Retrieved January 30, 2019 from https://quillette.com/2018/11/18/how-ritualized-apologies-areundermining-freedom-of-expression/.

Allen, C. (2015). The transgender triumph. Weekly Standard. Retrieved January 30, 2019 from https://www.weeklystandard.com/charlotteallen/the-transgender-triumph/.

Carey, B. (2004). Long after Kinsey, only the brave study sex. New York Times. Retrieved January 30, 2019 from https://www.nytim es.com/2004/11/09/health/long-after-kinsey-only-the-brave-study -sex.html.

Denizet-Lewis, B. (2014). The scientific quest to prove that bisexuality exists. New York Times Magazine. Retrieved January 30, 2019 from https://www.nytimes.com/2014/03/23/magazine/the-scientific-quest -to-prove-bisexuality-exists.htm/.

Devlin, A. (2017). Women's studies and the rise of the social justice warrior. Global Freedom Movement. Retrieved January 30, 2019 from https://globalfreedommovement.org/womens-studies-and-the-riseof-the-social-justice-warrior/.

Edsall, T. B. (2012). Studies: Conservatives are from Mars, liberals are from Venus. The Atlantic.com Retrieved January 30, 2019 from https ://www.theatlantic.com/politics/archive/2012/02/studies-conservati ves-are-from-mars-liberals-are-from-venus/252416/.

First They Came. (n.d.). In Wikipedia. Retrieved January 11, 2019, from https://en.wikipedia.org/wiki/First_they_came_.../.

Gender Studies. (n.d.). In Wikipedia. Retrieved January 11, 2019, from https://en.wikipedia.org/wiki/Gender_studies/.

Green, R. (2018). Gay rights, trans rights: A psychiatrist/lawyer's 50-year battle. (n.p.): Author.

Gross, P. R., Levitt, N., \& Lewis, M. W. (1996). The flight from science and reason. New York, NY: New York Academy of Sciences.

Hsu, K. J., Rosenthal, A. M., Miller, D. I., \& Bailey, J. M. (2016). Who are gynandromorphophilic men? Characterizing men with sexual interest in transgender women. Psychological Medicine, 46(4), 819-827.

Ioannidis, J. P. (2005). Why most published research findings are false. PLoS Medicine, 2(8), e124. https://doi.org/10.1371/journ al.pmed.0020124.t001.

Lawrence, A. A. (2012). Men trapped in men's bodies: Narratives of autogynephilic transsexualism. New York: Springer.

Lindsay, J. A., Boghossian, P., \&Pluckrose, H. (2018). Academic grievance studies and the corruption of scholarship. Areo. Retrieved January 30, 2019 from https://areomagazine.com/2018/10/02/academic-griev ance-studies-and-the-corruption-of-scholarship/.

Lukianoff, G., \& Haidt, J. (2018). The coddling of the American mind: How good intentions and bad ideas are setting up a generation for failure. New York: Penguin Press.

Milrod, C. (2014). How young is too young: Ethical concerns in genital surgery of the transgender MTF adolescent. Journal of Sexual Medicine, 11(2), 338-346.

Milrod, C., \& Karasic, D. H. (2017). Age is just a number: WPATHaffiliated surgeons' experiences and attitudes toward vaginoplasty in transgender females under 18 years of age in the United States. Journal of Sexual Medicine, 14(4), 624-634. 
Orwell, G. (1969). In front of your nose 1945-1950. New York: Penguin Press.

Rieger, G., Chivers, M. L., \& Bailey, J. M. (2005). Sexual arousal patterns of bisexual men. Psychological Science, 16(8), 579-584.

Rind, B., Tromovitch, P., \& Bauserman, R. (1998). A meta-analytic examination of assumed properties of child sexual abuse using college samples. Psychological Bulletin, 124(1), 22-53.

Rosenthal, A. M., Sylva, D., Safron, A., \& Bailey, J. M. (2012). The male bisexuality debate revisited: Some bisexual men have bisexual arousal patterns. Archives of Sexual Behavior, 41(1), 135-147.

Saotome-Westlake, M. T. (2016). Reply to Ozymandias on autogynephilia [blogpost]. Retrieved January 30, 2019 from http://unremediatedgen der.space/2016/Oct/reply-to-ozy-on-agp/.

Steinmetz, K. (2014a). The transgender tipping point. Time Magazine, $183(22), 38-46$.

Steinmetz, K. (2014b). Why it's best to avoid the word 'transgendered'. Time. Retrieved January 30, 2019 from http://time.com/3630965/ transgender-transgendered/.
Stupple, A. (2014). Disgust, dehumanization, and the Courts' response to sex offender legislation. National Lawyers Guild Review, 71, $130-148$.

Transgender terms and labels. (n.d.). Retrieved from https://www.plann edparenthood.org/learn/sexual-orientation-gender/trans-and-gende r-nonconforming-identities/transgender-identity-terms-and-labels/.

Udry, J. R. (1993). The politics of sex research. Journal of Sex Research, $30(2), 103-110$.

4thWaveNow (2017). "The money is flowing” to "suck people in:" Vaginoplasty \& the case of Jazz Jennings. Retrieved January 30, 2019 from https://4thwavenow.com/2017/04/03/the-money-is-flowing-tosuck-people-in-vaginoplasty-the-case-of-jazz-jennings/.

Publisher's Note Springer Nature remains neutral with regard to jurisdictional claims in published maps and institutional affiliations. 